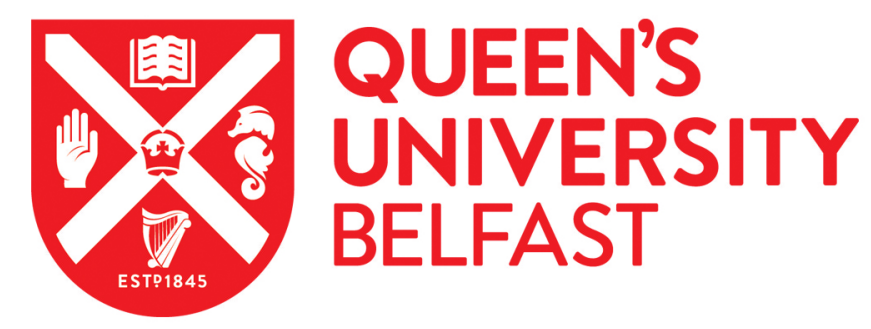

\title{
A large scale model experimental study of a tidal turbine in uniform steady flow
}

Atcheson, M., MacKinnon, P., \& Elsaesser, B. (2015). A large scale model experimental study of a tidal turbine in uniform steady flow. Ocean Engineering, 110(Part A). https://doi.org/10.1016/j.oceaneng.2015.09.052

\author{
Published in: \\ Ocean Engineering
}

Document Version:

Early version, also known as pre-print

Queen's University Belfast - Research Portal:

Link to publication record in Queen's University Belfast Research Portal

Publisher rights

(c) 2015 The Authors

\section{General rights}

Copyright for the publications made accessible via the Queen's University Belfast Research Portal is retained by the author(s) and / or other copyright owners and it is a condition of accessing these publications that users recognise and abide by the legal requirements associated with these rights.

Take down policy

The Research Portal is Queen's institutional repository that provides access to Queen's research output. Every effort has been made to ensure that content in the Research Portal does not infringe any person's rights, or applicable UK laws. If you discover content in the Research Portal that you believe breaches copyright or violates any law, please contact openaccess@qub.ac.uk. 


\title{
A large scale model experimental study of a tidal turbine in uniform steady flow
}

\author{
M. Atcheson*, P. MacKinnon and B. Elsaesser \\ Marine Energy Research Group, \\ Queen's University Belfast, \\ David Keir Building, Stranmillis Road, Belfast, BT9 5AG, UK \\ *E-mail: matcheson03@qub.ac.uk
}

\section{Abstract}

An experimental study measuring the performance and wake characteristics of a $1: 10^{\text {th }}$ scale horizontal axis turbine in steady uniform flow conditions is presented in this paper.

Large scale towing tests conducted in a lake were devised to model the performance of the tidal turbine and measure the wake produced. As a simplification of the marine environment, towing the turbine in a lake provides approximately steady, uniform inflow conditions. A $16 \mathrm{~m}$ long $\times 6 \mathrm{~m}$ wide catamaran was constructed for the test programme. This doubled as a towing rig and flow measurement platform, providing a fixed frame of reference for measurements in the wake of a horizontal axis tidal turbine. Velocity mapping was conducted using Acoustic Doppler Velocimeters.

The results indicate varying the inflow speed yielded little difference in the efficiency of the turbine or the wake velocity deficit characteristics provided the same tip speed ratio is used. Increasing the inflow velocity from $0.9 \mathrm{~m} / \mathrm{s}$ to $1.2 \mathrm{~m} / \mathrm{s}$ influenced the turbulent wake characteristics more markedly. The results also demonstrate that the flow field in the wake of a horizontal axis tidal turbine is strongly affected by the turbine support structure.

Keywords: tidal turbine, experimental modelling, large scale, wake, performance, ADV

\section{Introduction}

The tidal energy industry is reaching commercial status following an increase in the deployment of prototype tidal energy converters (TEC) in recent years. Once tidal technologies have been demonstrated through prototype testing, the installation of multiple devices in arrays is expected to follow. In order to identify the optimum layout of an array, knowledge of the wake generated by a TEC device is required. Using information about the wake of an upstream device, developers can make a more informed judgement on initial array layouts.

The tidal flow regime is complex with a number of contributory factors resulting in an unsteady, non-uniform flow that includes varying scales of turbulence. Some contributions to variable flow generation at tidal sites include the local bathymetry, seabed roughness and turbulence generated by wind and swell-induced waves (Boake et al., 2009; Myers and Bahaj, 2008). When a tidal device is deployed in a high energy tidal site it adds to the factors affecting the flow. The device support structure and rotating turbine both generate turbulence, but the scale and intensity of turbulence generated at full scale has had minimal coverage in publications at present. Information relating to the combination of all the contributing turbulent flow fields will become more important when tidal energy devices are deployed in arrays, as the flow field in the wake of a device will affect the inflow conditions for turbines located downstream.

The exact form of the wake created by a TEC may be device-specific, but the fundamental wake characteristic can be decomposed into two distinct regions: a near wake and a far wake 
region (Lissaman, 1979). The near wake region is located directly behind a turbine, where coherent turbulent structures generated from the turbine can be detected. The difference in velocity between the slower-moving fluid in the wake and the free stream flow produces a shear layer along the wake boundary. In the shear layer eddies are formed, which help to mix the lower velocity fluid in the wake with the higher velocity fluid surrounding the wake. This mixing process transfers momentum into the wake and increases the flow velocity. The distance downstream where the shear layer becomes thick enough to meet the turbine wake axis is used to mark the end of the near wake region and the start of the far wake. In wind turbine wake studies this transition point has been detected between two to five rotor diameters downstream of the turbine (Vermeer et al., 2003).

In the far wake, turbulent mixing gradually decomposes the wake and through entrainment with the surrounding flow increases the size of the wake. The ambient turbulence conditions have been shown to influence the rate of recovery of the wake velocity with downstream distance (Mycek et al., 2014). Similarly Medici and Alfredsson (2005) measured the influence of the free-stream turbulence on the wake recovery of a wind turbine. The results show that the initial reduction in velocity was similar for both cases, but with distance from the turbine (approximately three rotor diameters downstream) the recovery of the wake velocity was enhanced due to higher ambient turbulence levels.

Far wake characteristics may be considered most useful for inter-device spacing within an array. However, decisions on inter-array spacing may also benefit from an increased understanding of the near wake and information about fluid structure interactions around a TEC. Near wake studies are particularly beneficial to investigate any influence the turbine (and support structure) geometry may have on the wake characteristics, specifically any measureable coherent turbulent structures (Afgan et al., 2013; Chamorro et al., 2013) and the combined influence of the turbine and support structure (Myers and Bahaj, 2009). Following a comparison between numerical modelling methods, and using the experimental results from Chamorro et al (2013), Kang et al. (2014) concluded that due to the apparent link between the wake meandering mechanism and the hub vortex structure, the consideration of the geometry of the turbine near the hub region was critical (for the turbine studied) to accurately resolve the mean flow and dynamic characteristics of the far wake. Near wake experimental studies also support identification of the beginning of the far wake region (i.e. a self-similar twodimensional wake) downstream of a device (Stallard et al., 2015).

The majority of flow field studies around tidal turbines have been carried out in the laboratory (e.g. Good et al., 2011; Rose et al., 2011; Stallard et al., 2015) or at small scale in the field (Birjandi et al., 2012; Sun, 2008). Porous discs have been used in small scale investigations to study the far wake characteristics of horizontal axis turbines on the assumption that the far wake characteristics are similar to a full scale rotor if the thrust on the rotor and channel properties are correctly scaled (Harrison et al., 2008; Myers and Bahaj, 2010). A summary of published tidal stream turbine wake studies can be found in Tedds et al. (2014).

Porous discs have also been used for wind turbine wake studies in the laboratory (Builjtes, 1978; Sforza et al., 1981). However, there are some principle differences between a porous disc and a rotor which make it unsuitable for near wake studies, namely there is no mechanical power generated by the flow and vortices shed from a disc differ from those from a turbine. Using a rotor to model horizontal axis turbines at smaller scales incurs scaling issues as described by Myers and Bahaj (2010). Another factor which must be taken into account is the blockage ratio between the channel and rotor cross sectional areas. Single prototype tidal stream turbines in a full scale environment operate in a relatively unconstrained flow and a low blockage ratio in laboratory tests should be maintained to reflect these conditions at full 
scale. It has been shown by Whelan et al. (2009) that a high blockage effect in a channel could significantly increase the amount of power extracted from the flow by a single turbine.

Conducting larger scale model experiments using a rotor permits a more representative study of the flow field in the near wake. Taking into consideration scaling and blockage effects, Myers and Bahaj (2009) chose a rotor diameter of $0.8 \mathrm{~m}$ (considered to be $1: 20^{\text {th }}$ scale) to conduct experiments in the near wake of a tidal turbine.

Experiments carried out in the laboratory provide controlled test conditions, with a high degree of accuracy, repeatability and a greater coverage of the wake can be obtained more readily at smaller scales. Large scale field tests are inherently more uncontrollable and difficult to conduct than laboratory experiments, but can provide a valuable step in the development of commercial tidal devices. The motivation for the towing tests presented was to simplify the operating conditions to which a large scale turbine model would be exposed at a nursery site in Strangford Lough. The approach was adopted following initial sea trials of the Evopod model highlighted the difficulties of isolating wake characteristics in the highly variable test environment. Carrying out towing tests, as a precursor to large scale sea trials, provides the potential to characterise the model performance and wake generated (under steady uniform conditions) which may prove valuable in the interpretation of data gathered during the sea trials. The large scale towing tests also provide the opportunity to test the functionality of a model and ensure all device components are working correctly before deploying the device in a less accessible tidal environment.

The large scale towing tests were conducted as part of the SuperGen Marine Energy Research Consortium Phase 2 (SuperGen Marine, 2012) to contribute to the understanding of the hydrodynamic performance of a tidal turbine. This included the estimation of the interaction of the turbine with the incoming steady, uniform flow and the subsequent wake generated. Understanding the processes associated with a single tidal turbine in steady uniform inflow conditions can be seen as the first step to understanding the interaction between multiple turbines.

In this study, model performance tests and wake flow characterisation of a $1: 10^{\text {th }}$ scale horizontal axis tidal turbine (rotor diameter of $1.5 \mathrm{~m}$ ) were conducted at a large towing test facility, which was specifically designed for the experimental campaign by the authors. As a simplification of the marine environment, the lake provides in principle steady, uniform flow conditions to a tidal turbine towed through the water. An assumption made within the scope of the towing test is that the wake results will be reflective of a tidal device operating in moving water. In towing tests momentum is introduced into the wake by the vessel and the rotating turbine, therefore the flow velocity measured in the wake is relative to the towing platform, as opposed to the absolute flow velocity measured in the wake of a device in a channel of moving water. Results from previous wake measurement campaigns, carried out by Sun (2008), showed that although the real operating condition for a tidal turbine is water moving past a device, similar wake results were obtained when the same device (a $250 \mathrm{~mm}$ porous disc) was tested in a towing tank and a moving water channel.

This paper describes the large scale towing test facility designed and constructed for model performance and near wake flow field studies. An experimental campaign using the $1: 10^{\text {th }}$ scale Evopod horizontal axis tidal turbine device developed by Oceanflow Energy Limited is detailed. Model performance and near wake characteristics results are presented for varying inflow conditions. 


\section{Methodology}

Forward motion at uniform speed through the lake environment provides an approximation to steady uniform inflow conditions, achieved when towing the model through a body of still water. These experiments allowed the change in steady uniform flow conditions due to the presence of the tidal device to be quantified, before adding the complexity of the unsteady non-uniform inflow conditions which are typically in tidal flow. The towing experiment described here was planned as a precursor to carrying out tests at a large scale model test site in Strangford Lough, Northern Ireland. The selection criteria for the test site were based on a full scale peak flow of $3 \mathrm{~m} / \mathrm{s}$ and $60 \mathrm{~m}$ water depth. At $1: 10^{\text {th }}$ scale this is equivalent to a peak flow of $0.95 \mathrm{~m} / \mathrm{s}$ and a $6 \mathrm{~m}$ water depth. Following a site selection process by Queen's University Belfast (Boake et al., 2009), the site that exhibited the closest match to the desired $1: 10^{\text {th }}$ scale characteristics was chosen, with a depth of $6 \mathrm{~m}$ (mean tide level) and peak velocity of $1.2 \mathrm{~m} / \mathrm{s}$. This site is now known as the Portaferry tidal test site.

Prior to undertaking the towing tests, a significant amount of preparatory work was required including: the establishment of the towing facility, design and construction of the towing rig and the traversable flow measurement platform (including the design of bespoke mounting arrangements for the velocity measurement instruments). Details of the test site, towing rig, tidal turbine test model and the experiment methodology are described herein; further information on the experimental methodology can be found in Atcheson (2013).

\subsection{Towing test site}

The test site, Montgomery Lough (also in Northern Ireland), is a small lake approximately 400 $\mathrm{m}$ in length and $133 \mathrm{~m}$ wide. Prior to the towing test, a bathymetric survey of the lake was conducted to identify a suitable length over which to carry out the towing experiments. A length of approximately $200 \mathrm{~m}$ with an average water depth of $6 \mathrm{~m}$ was identified (Figure 1).

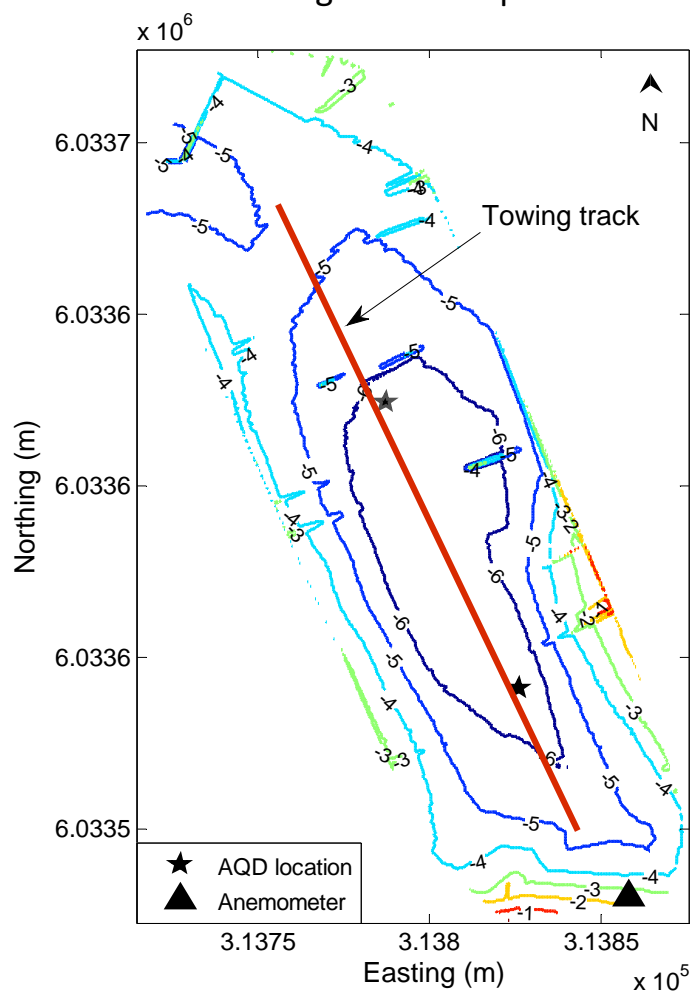

Figure 1: Bathymetry contour plot of Montgomery Lough (including approximate AQD deployment locations and installed weather station anemometer). 
A bottom-mounted Nortek 2.0 MHz Aquadopp Profiler (AQD) was deployed to observe the natural currents in the lake. The AQD was deployed at two different locations along the towing track, for a period of five days at each location (Figure 1). An average water velocity of 0.06 $\mathrm{m} / \mathrm{s}$ was measured between the depths of $0.6 \mathrm{~m}$ and $2.6 \mathrm{~m}$ below the water surface, where the model rotor operates. The average observed water velocity was equivalent to less than $7 \%$ of the slowest target towing speed of $0.9 \mathrm{~m} / \mathrm{s}$. The results show that the underlying ambient current within the lake is minimal and the ambient turbulence intensity in the lake is $<2 \%$. Given such low flow velocities, the difference may be due to the high Doppler noise relative to the Doppler shift signal (low SNR) and thus in fact even smaller, though the data does not allow proof of this.

\subsection{Towing rig}

With the support of Wavebarrier Ltd (a specialist marine operations company), a custom-built towing rig was designed and constructed to tow the large scale TEC model through the lake. The towing rig used is a $16 \mathrm{~m}$ long $\times 6 \mathrm{~m}$ wide catamaran (Figure 2). The towing rig also doubled as a measurement platform, providing a fixed frame of reference for measurements downstream of the turbine. The available downstream flow measurement area, once a test model is attached at the front of the rig and allowing for the working deck at the back of the rig (where the wheel house and work bench are located), is approximately $8 \mathrm{~m}$ in length by 5 $\mathrm{m}$ width. A single engine drives the towing rig and is located in the centre of the deck structure at the rear of the rig. The engine and the deck are both mounted on rubber pads to reduce transmission of engine vibrations.

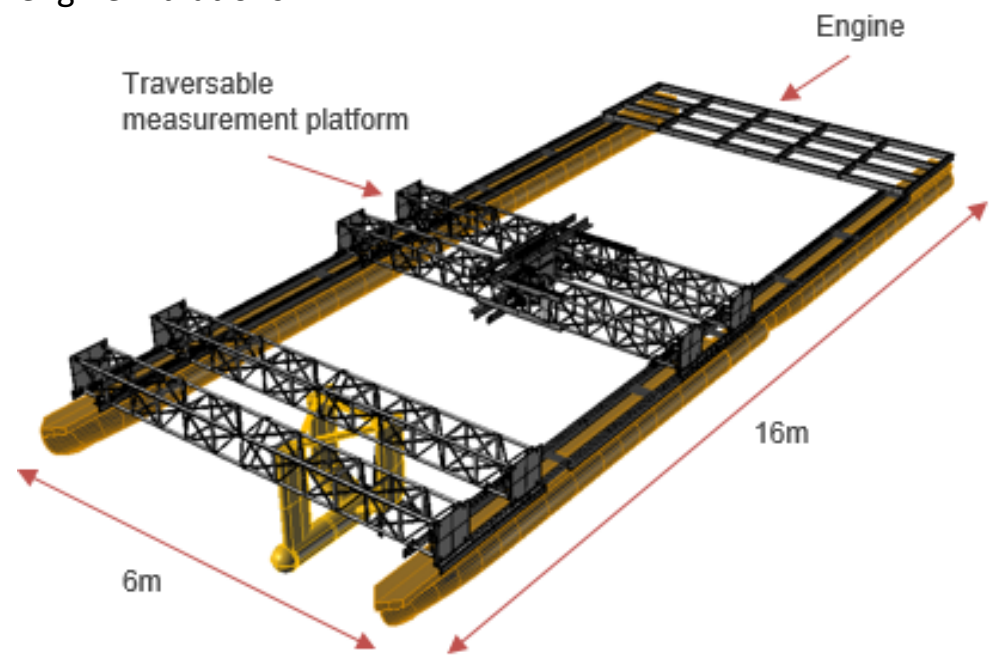

Figure 2: The towing test rig.

A real-time velocity reading was required by the towing rig driver to set and monitor the towing speed. A flow velocity profile was also required as a record of the inflow conditions that the model was exposed to for each towing test, to record any deviation between the target and actual towing speeds (Table 2). An Aquadopp Profiler (AQD) was located at the front of the rig for this purpose. A paddlewheel speed log (Advansea S400 Series) was used to provide the towing rig driver with a real-time speed reading. This was calibrated with the AQD prior to the towing tests. The towing track was marked out using marker buoys and a digital compass was available to the driver to set and monitor the heading of the towing rig during each test.

\subsection{Tidal energy converter test model}

Oceanflow Energy's 1:10 ${ }^{\text {th }}$ scale Evopod model was used in the experiments. Evopod is a semisubmerged, floating, tethered device which extracts energy from bi-directional tidal stream flows (for further details see Oceanflow Energy (2007)). The tethered mooring arrangement is 
the intended method of deployment for the model, but in the towing tests the model was rigidly fixed to the towing rig. Bespoke clamps were manufactured and attached to the Evopod support structure to rigidly attach the model onto the towing rig. Due to the commercially sensitive nature of device specific information, the device support structure dimensions are not detailed, but further information can be found in Mackie (2008). Figure 3 illustrates the Evopod model (including the clamps) ready for deployment at Montgomery Lough.

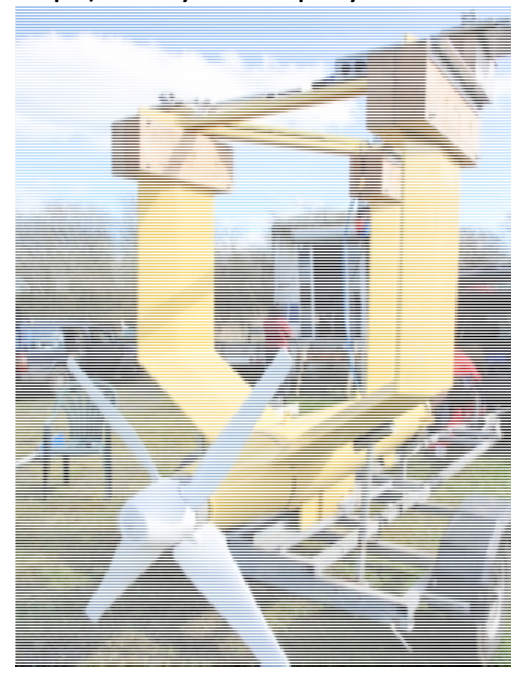

Figure 3: Evopod 1:10 ${ }^{\text {th }}$ scale test model.

The Evopod model scaling is based on a target set of parameters for a full scale device deployed in the Pentland Firth. Table 1 presents key operational parameters for a full scale and 1:10 ${ }^{\text {th }}$ scale Evopod device specified by the device developer (Mackie, 2008).

Table 1: Evopod operational parameters.

\begin{tabular}{|l|c|c|}
\hline & Full scale (Pentland Firth) & $\mathbf{1 : 1 0}^{\text {th }}$ scale \\
\hline Turbine diameter (m) & 15.0 & 1.5 \\
\hline Rated output (kW) & 1800 & 0.57 \\
\hline Rated flow speed $(\mathbf{m} / \mathbf{s})$ & 4.0 & 1.26 \\
\hline
\end{tabular}

The corresponding Froude number, $\mathrm{Fr}$, is 0.16 and the Reynolds number, Re, (based on the rated flow speed and turbine radius) is $3.0 \times 10^{7}$ at full scale, compared to $9.4 \times 10^{5}$ at $1: 10^{\text {th }}$ scale. In general, researchers have tolerated the discrepancy between model and prototype Reynolds numbers by setting the conditions that Froude scaling is maintained and that the model and full scale Reynolds numbers lie within the same turbulent classification (i.e. $>10^{5}$ for the case presented) (Myers and Bahaj, 2010). Results presented by Tedds et al. (2011) also indicate that if $\operatorname{Re}>2.4 \times 10^{5}$ any Reynolds number dependency on turbine performance is weak. In terms of the Reynolds number effect on the wake shape, similar flow patterns are assumed to occur when the device shape and Reynolds numbers range match.

The Evopod horizontal axis rotor is $1.5 \mathrm{~m}$ in diameter and has four fixed-pitch blades. The blades are composed of Eppler 387 low Reynolds number aerofoil sections. The rotor is attached downstream of the device support structure. The blades are connected to the shaft of the device via a hub, which uses a taper lock coupling to fasten the turbine onto the nacelle. The main shaft links the drive train from the hub through to the generator. The shaft torque is measured using a torque transducer (TorqSense digital RWT321) which is located downstream of the hub and before the gearbox on the main shaft. Flexible couplings on either side of the torque transducer are used to link the instrument with the main shaft. A two-stage gearbox is used to provide a combined gear ratio of 1:10 and a generator converts the mechanical energy generated by the rotating turbine into electrical energy. 
The Evopod model was designed to be grid-connected at the Portaferry tidal test site in Strangford Lough. However, during the towing tests the model acted as a stand-alone machine that required speed control and a means of dumping excess power produced. Five load resistors, connected in parallel, were used to apply additional resistance to the generator, controlling the rotational speed of the turbine. The resistance bank was sealed between two aluminium plates, which dump the power produced through heat dissipation. Communication with the device was made via a wireless Wi-Fi link and data was acquired using a data acquisition card. Oceanflow Energy wrote a proprietary data acquisition code to communicate with the model. During the towing experiments the model sensors were set to sample at a rate of $9 \mathrm{~Hz}$.

\subsection{Flow measurement \& mapping}

In order to map the flow downstream of the model, point measurements were taken using a Nortek Vector Acoustic Doppler Velocimeter (ADV). The ADV was set to sample at $64 \mathrm{~Hz}$ with a sampling volume of $18 \mathrm{~mm}^{3}$ located at a distance of $157 \mathrm{~mm}$ from the probe. An ADV measurement matrix was defined relative to the centre of the turbine. The measurement grid was specified in terms of the model turbine diameter $(D=1.5 \mathrm{~m})$. Downstream measurements extended from 0.5D to 5D along the longitudinal axis and laterally to 0.75D. Measurements were taken along a horizontal plane, coinciding with the turbine's axis, at a depth of $1.285 \mathrm{~m}$ below the water surface. In total, 22 single point measurements were made; the locations of these are illustrated in Figure 4 and Figure 5. Measurements were limited to one half of the wake. Measurements were made at each matrix location for a period of one 'run' (or traverse of the lake), not taking into account repeatability runs. The sampling period for a run at towing speed of $1.2 \mathrm{~m} / \mathrm{s}$ was equal to 170 seconds, resulting in over 10,000 sampling points.
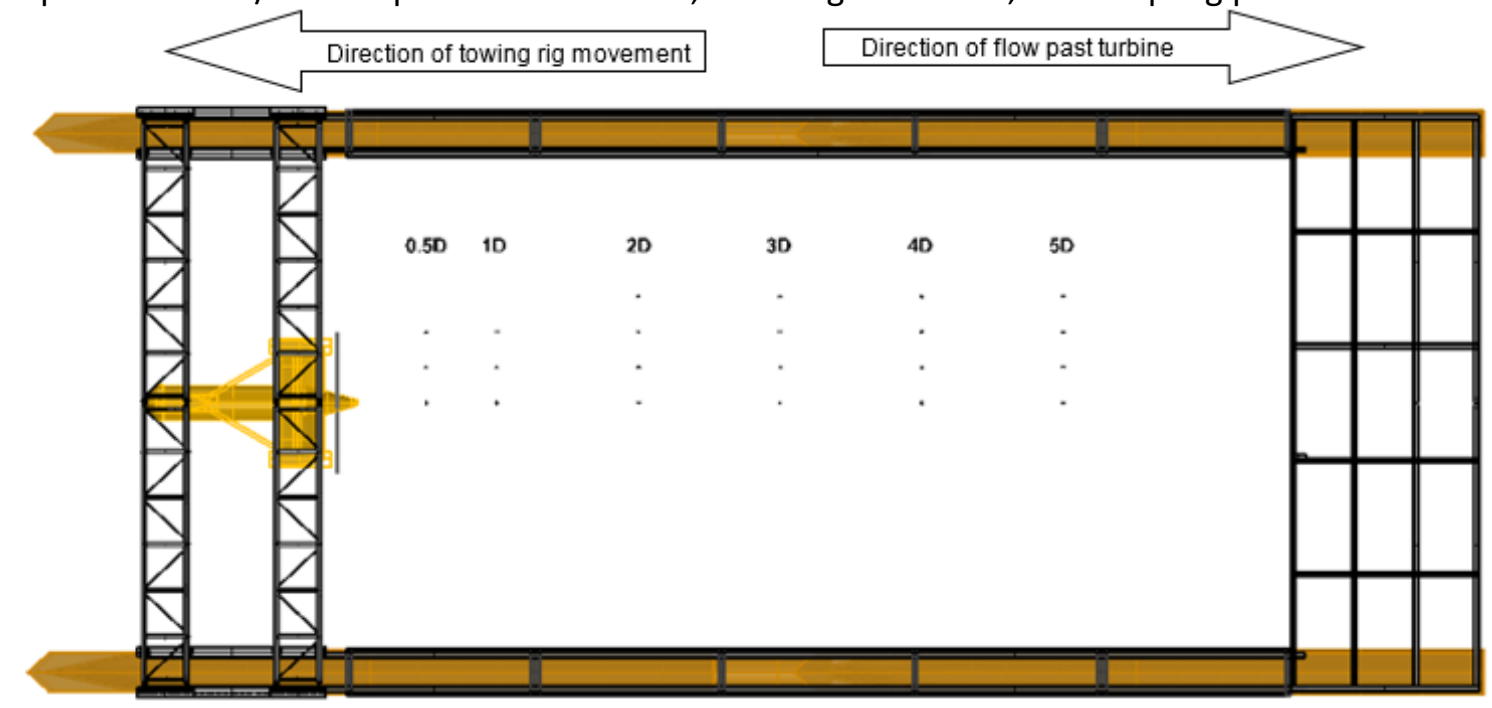

Figure 4: Plan view of Evopod positioned on the towing rig and the ADV measurement matrix downstream. 


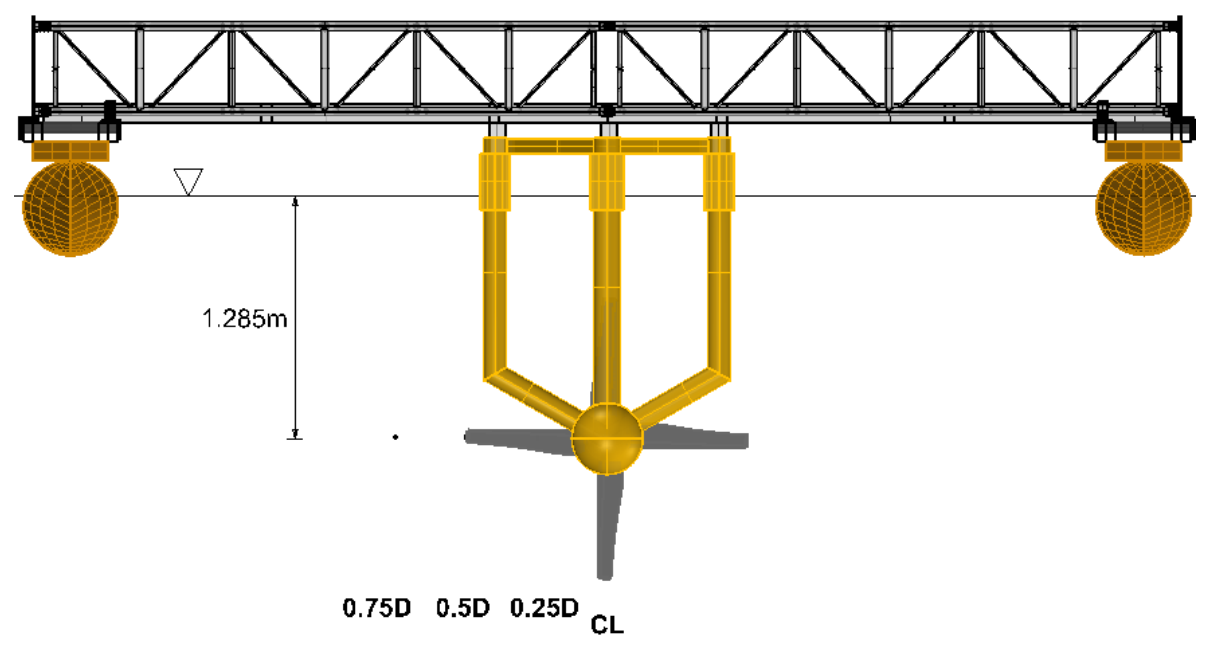

Figure 5: Front view of Evopod positioned on the towing rig, and the ADV measurement matrix.

\section{Data quality and accuracy}

\subsection{Large scale experiment variables}

Carrying out the experiment in a lake is more controllable than deploying the model at a real tidal flow site, but inevitably less controllable than experiments carried out under laboratory conditions. Key details of the site conditions and potential variables which may affect flow conditions, and thus experimental accuracy, must be taken into account.

Variables which were identified at the beginning of the experiment included:

1. currents being set up in the lake due to wind conditions;

2. hull effects from the towing rig pontoons;

3. vibration of the instrument mounting structures;

4. the ability of the towing rig to achieve and maintain a constant steady speed;

5. the repeatability of results.

In order to account for each of these variables, precautionary measures were implemented where possible. Steps taken to quantify experimental variables included:

1. Weather data was recorded using an Oregon Scientific Professional Weather Centre, Model WMR200. An anemometer was installed on a mounting arrangement in the south-east quadrant of the lake (Figure 1). A correlation between wind speed and lake velocity measurements indicated that a moderate to strong breeze (wind speed of $>6.5 \mathrm{~m} / \mathrm{s}$ ) at the lake could induce a surface velocity in excess of $0.1 \mathrm{~m} / \mathrm{s}$. Experimental work at the lake was therefore limited to days when calm wind conditions (i.e. wind speeds $<6.5 \mathrm{~m} / \mathrm{s}$ ) prevailed. The wind conditions were monitored daily using the weather station anemometer specifically installed for the experimental campaign.

2. Preliminary towing tests were carried out with no test model in place to determine if there was a noticeable wake created by the catamaran hulls, which may influence the wake measurements. Two Aquadopp Profilers (AQDs) were deployed on the towing rig, one mounted along the central axis of the towing rig and the other mounted at an offset of $1.5 \mathrm{~m}$ from the central axis (equivalent to a distance of 1D). Simultaneous velocity measurements were taken by the Aquadopp Profilers at five locations; equivalent to the measurement locations: 0.5D, 1D, 2D, 3D and 4D in the wake of Evopod (as presented in Figure 4). 
The average velocity results were analysed to examine if there was any visible trend in the data due to the location of the instruments relative to the hull. Figure 6 presents the difference between the AQD measurements relative to towing speed (measured by the AQD mounted on the central axis of the towing rig). The results show that the greatest difference between the AQD measurements was at the slowest towing speeds. As the towing speed increases the difference between the AQD measurements reduces to a level that could be considered as background noise. Overall, the results provide reasonable certainty that any wake created by the catamaran hulls does not significantly influence the flow in the wake measurement region of the towing rig.

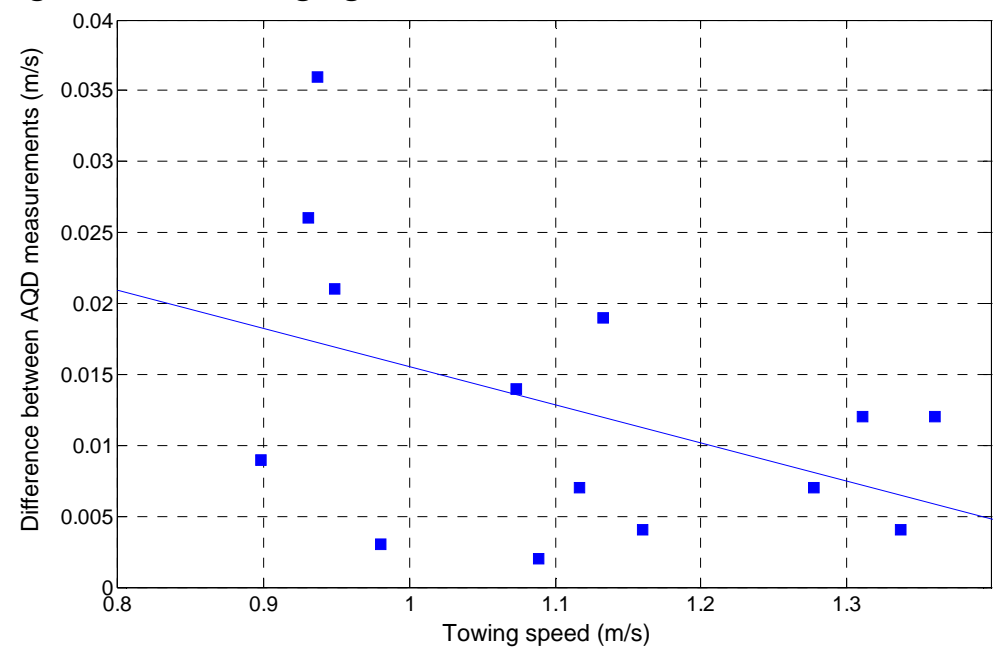

Figure 6: Difference between the Aquadopp Profiler (AQD) velocity measurements relative to towing speed.

3. A three metre long modular hydrofoil-shaped mounting structure was designed and manufactured to facilitate the mounting of multiple ADVs along the strut. Figure 7 shows the assembly, with two ADVs mounted in the structure, ready for deployment at the test site. A bespoke clamp was designed to hold the ADV mounting strut rigidly in place on the towing rig (Figure 7). The mounting structure permitted simultaneous ADV measurements to be made at different depths through the water column. During the preliminary test campaign (with no model in place on the towing rig) ADV data was collected using the strut in place on the towing rig. A frequency analysis of the velocity data showed that no vibrations on the strut were detected.
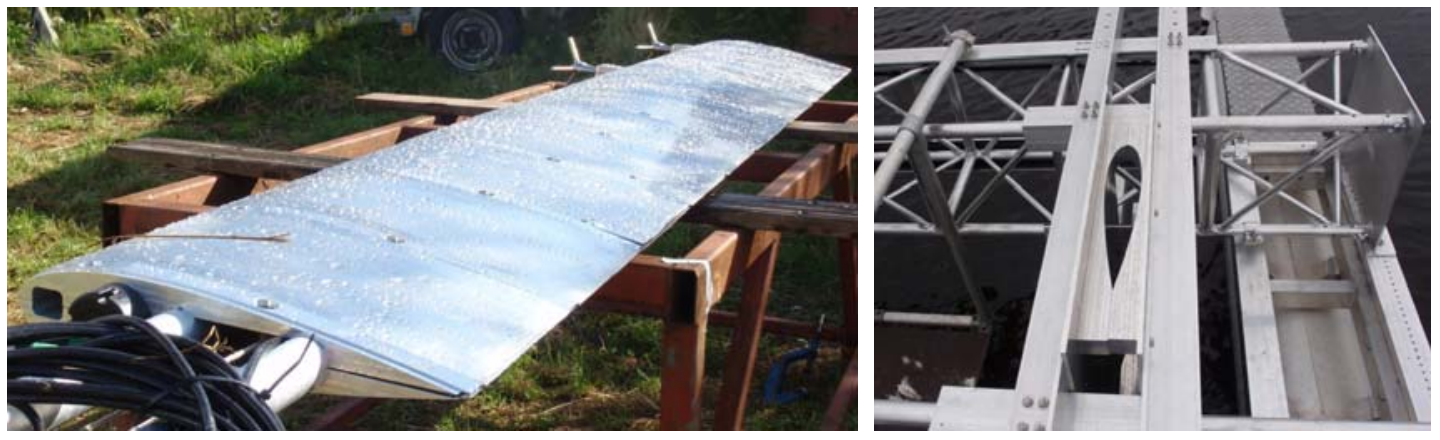

Figure 7: Assembled hydrofoil strut (left), hydrofoil clamp in place on the towing rig (right).

4. The measured longitudinal approach velocities were compared with a target towing speed $(1.2 \mathrm{~m} / \mathrm{s})$ to quantify any deviation from the intended water velocity relative to the Evopod model. Results from a sample set of experimental runs are shown in Table 2. Under laboratory conditions a mean velocity variation of $\pm 1 \%$ between runs is achievable (Myers and Bahaj, 2010). In the towing experiment the inflow velocity varied more considerably, with 
differences of up to $10 \%$ of the target towing speed recorded in some runs, but overall $86 \%$ of towing tests were within $5 \%$ of the target towing speed.

Table 2: Comparison between the target towing speed and measured AQD results.

\begin{tabular}{|c|c|c|}
\hline $\begin{array}{c}\text { Mean longitudinal } \\
\text { velocity }(\mathbf{m} / \mathbf{s})\end{array}$ & Standard deviation $\mathbf{( m / s )}$ & $\begin{array}{c}\text { Deviation from target } \\
\text { speed (\%) }\end{array}$ \\
\hline 1.22 & 0.07 & 1.4 \\
\hline 1.19 & 0.06 & 0.6 \\
\hline 1.24 & 0.05 & 3.2 \\
\hline 1.16 & 0.06 & 3.7 \\
\hline 1.14 & 0.06 & 5.1 \\
\hline 1.16 & 0.04 & 3.2 \\
\hline 1.16 & 0.07 & 3.3 \\
\hline 1.19 & 0.05 & 0.5 \\
\hline 1.23 & 0.02 & 2.8 \\
\hline 1.19 & 0.03 & 0.7 \\
\hline 1.21 & 0.06 & 0.6 \\
\hline 1.17 & 0.07 & 2.3 \\
\hline
\end{tabular}

In order to investigate the steadiness of the towing speed over the duration of a run, time series data for individual tests were investigated. Low frequency variations in the measured velocity datasets were detected and believed to be due to the difficulty in maintaining a consistent towing rig speed to such a high tolerance at such a low speed for the towing rig.

The time-variant nature of the towing speed is unsuitable for estimating statistical parameters i.e. the turbulence intensity (which, in its standard form, quantifies the magnitude of the velocity fluctuations about a steady mean value). In order to compensate for the unsteady towing speed a moving average was applied in the analysis of the ADV data. The number of consecutive points incorporated in the moving average applied was based on preliminary towing test investigations, where velocity measurements were taken simultaneously by two ADVs deployed at different depths with no model in place. A similar low frequency variation in velocity was common to both ADVs, which supported the hypothesis that the variations in speed were directly related to the towing speed of the rig.

5. A limited number of repeatability tests were incorporated into the model tests to assess the similarity of the wake characteristics for different tests. The ADV data was collected at the same location in the wake, for three separate towing tests under similar conditions. Table 3 presents repeatability results collected in the wake of Evopod (see Section 4 for a description of the variables presented). The findings suggest that if the towing speed remains consistent, results for the same measurement point in the wake are also similar.

Table 3: Repeatability of the results in the wake of Evopod.

\begin{tabular}{|c|c|c|c|c|c|}
\hline $\begin{array}{c}\text { Towing } \\
\text { speed } \\
(\mathbf{m} / \mathbf{s})\end{array}$ & $\begin{array}{c}\text { Mechanical } \\
\text { power } \\
(\mathbf{W})\end{array}$ & $\boldsymbol{C}_{\boldsymbol{p}}$ & $\begin{array}{c}\text { Velocity } \\
\text { deficit } \\
(\mathbf{)}\end{array}$ & $\begin{array}{c}\text { Turbulence } \\
\text { intensity } \\
(\mathbf{\%})\end{array}$ & $\begin{array}{c}\text { TKE } \\
\left(\mathbf{m}^{\mathbf{2}} / \mathbf{s}^{\mathbf{2}}\right)\end{array}$ \\
\hline 1.01 & 250 & 0.28 & 0.30 & 8.08 & 0.011 \\
\hline 1.03 & 266 & 0.28 & 0.32 & 8.83 & 0.012 \\
\hline 1.01 & 243 & 0.27 & 0.31 & 8.98 & 0.012 \\
\hline
\end{tabular}




\subsection{Data pre-processing}

The measured ADV velocity signal was decomposed into mean and fluctuating components (Equation 1). The fluctuating component is of primary importance to the calculation of the wake turbulence properties. In the towing experiments, a moving average was used to represent the mean velocity component $(\bar{u})$ for each dataset.

$$
u(t)=\bar{u}+u^{\prime}(t)+u_{e}(t)
$$

Authors reporting on the use and analysis of ADV data (Goring and Nikora, 2002; Lohrmann et al., 1994; Wahl, 2003) have pointed out that the raw ADV output data includes the combined effects of velocity fluctuations $\left(u^{\prime}\right)$, Doppler (instrument) noise, and potential sampling errors depending on the instrument deployment arrangement and settings (collectively $u_{e}$ ). The raw instantaneous axial velocity signal measured contained some spurious, large-amplitude spikes. Therefore, prior to the analysis of the velocity components, an ADV pre-processing procedure of the raw velocity signal was applied (Figure 8).

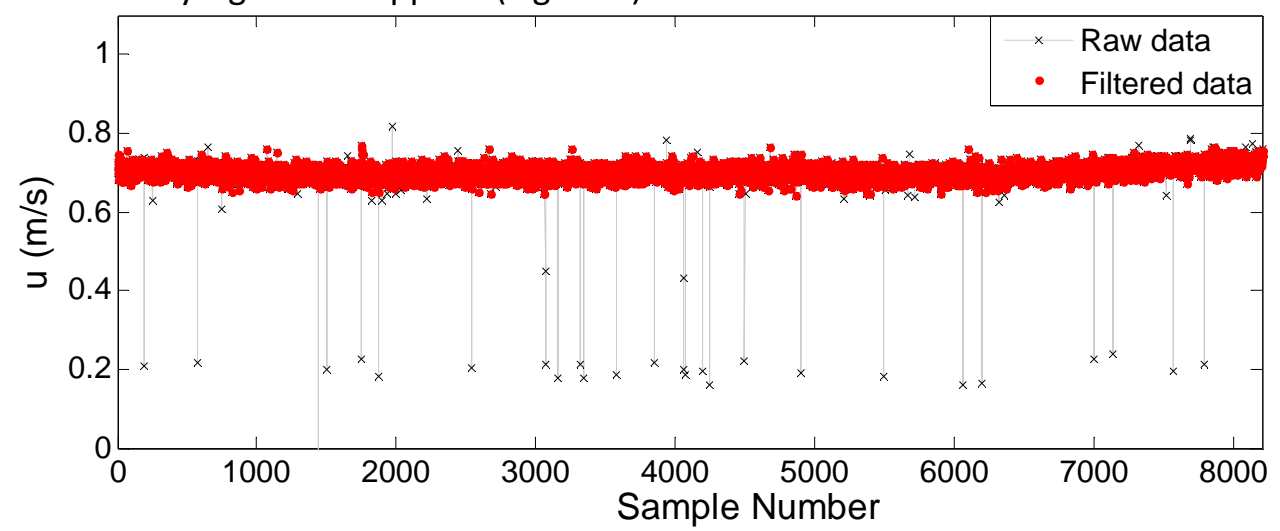

Figure 8: Velocity data time series for unfiltered and filtered conditions (sampling rate $=64 \mathrm{~Hz}$ ).

The ADV data outputs include the 3D instantaneous velocity $(u, v, w)$, the signal to noise ratio (SNR) and the correlation (COR). The SNR and COR data are calculated to indicate the quality of the instantaneous velocity estimates. The recommend acceptable limits are SNR $>15$ and COR $>70$ (SonTek, 2001). An ADV pre-processing procedure was implemented to check the quality of the measured data and remove any potentially erroneous data points.

A two-step filtering process, which imposed signal-to-noise (SNR) and correlation (COR) limits, and a de-spiking filter were applied to the raw ADV data sets recorded. The modified phasespace threshold filter by Mori et al. (2007) was selected. This filter evaluates the fluctuating component of the variable, its first time derivative and second time derivative using a three dimensional Poincaré map (phase-space plot). Data points are assumed to be of good quality if they lie within the bounds of an ellipsoid. The major and minor axes of the ellipsoid are calculated using the standard deviation $(\sigma)$ of the fluctuating component of the variable and the first and second time derivatives together with a Universal threshold $c$, which was first used in signal filtering applications by Donoho and Johnstone (1994). Using the Universal threshold removes the need to individually calculate the threshold applied by the filter to each data set, speeding up the filtering process.

Any data points that lie outside the bounds of the ellipsoid were removed and replaced using a third order polynomial function, fitted through the data on either side of the spike removed from the signal. Overall, the ADV data sets were of high quality: SNR values were consistently high ( $>48$ ) due to the high concentration of suspended particulate matter in the lake (the particles aid ADV measurement). The data was well correlated with the average COR for each traverse consistently higher than 88 . 


\section{Results and discussion}

\subsection{Flow field with different test configurations}

The Evopod model has a relatively large support structure, comprising three mounting struts and a long cylindrical nacelle. Initially there was concern that the wake generated by the model support structure would overshadow the turbine-generated wake component. Preliminary tests were carried out to assess the wake created by the device support structure. Using a target towing speed of $1.2 \mathrm{~m} / \mathrm{s}$, measurements were taken in the wake at the same location for three different test configurations:

1. Evopod complete with its turbine;

2. Evopod with just its support structure (turbine rotor removed);

3. no model (undisturbed flow).

One of the primary wake characteristics of interest is the velocity deficit ( $\left.u_{\text {deficit }}\right)$. The velocity deficit is a non-dimensional number, calculated using the upstream water velocity relative to the turbine at hub height $\left(\bar{u}_{0}\right)$ and the wake velocity $\left(\bar{u}_{w}\right)$ at the measurement location:

$$
u_{\text {deficit }}=1-\overline{u_{w}} / \overline{u_{0}}
$$

Figure 9 presents the velocity deficit on the vertical axial plane of the turbine, 1D downstream of the turbine's mounting position. It can be seen from Figure 9 that there is a significant velocity deficit within the swept area shadow of the turbine's rotor. A reduced, but still significant, velocity deficit due to the model's support structure is also clearly visible in the upper half of the water column when the turbine is removed. The axial turbulence intensity recorded along the centreline of the wake was $13 \%$, compared to $<5 \%$ in the wake of the centreline strut (at $0.3 \mathrm{D}$ and $0.6 \mathrm{D}$ above the turbine axis). Where the axial turbulence intensity $(\mathrm{TI})$ is defined as the standard deviation $(\sigma)$ divided by the mean axial velocity $(\bar{u})$.

$$
T I=\sigma / \bar{u}
$$

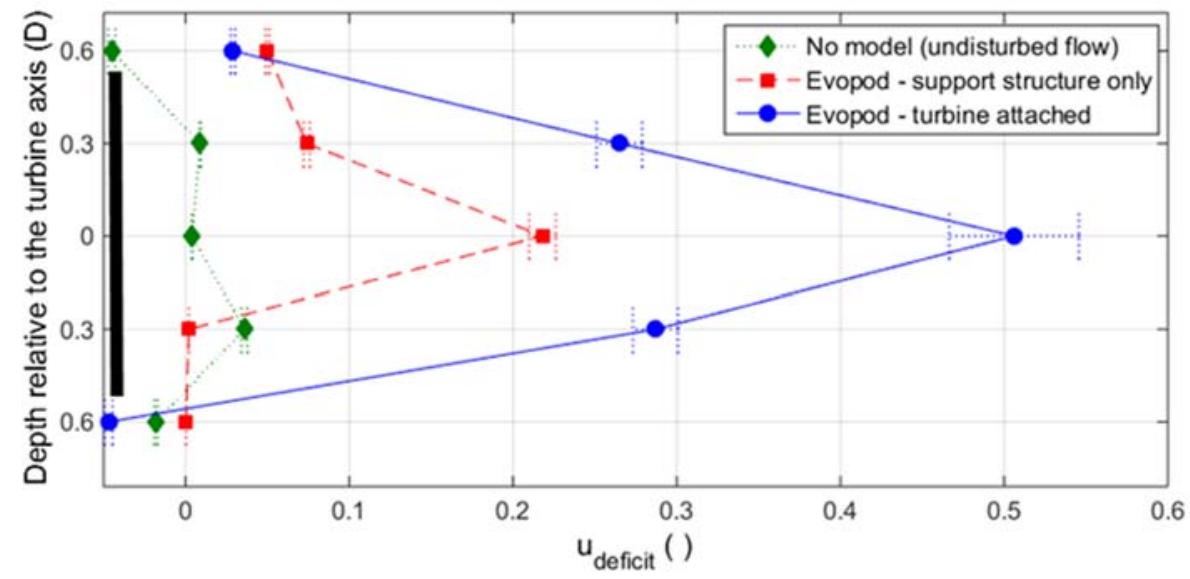

Figure 9: Comparison of velocity deficit profiles for different test configurations, measurements taken at 1D downstream of Evopod (rotor defined by the thick black line on the left) along the turbine axis (95\% confidence interval indicated by the error bars).

\subsection{Model performance for varying inflow speeds}

The power available to a TEC is directly related to the inflow velocity that the turbine is exposed to. In the towing tests this was measured by the AQD attached to the towing rig upstream of Evopod. The power available $\left(P_{K E}\right)$ in the flow is calculated assuming a uniform flow across the turbine swept area, based on a depth averaged velocity from the upstream AQD. 


$$
P_{K E}=\frac{1}{2} \rho A U_{0}^{3}
$$

where $\rho$ is the fluid density, $A$ is the swept area of the turbine and $U$ is the flow velocity. The relationship with velocity means that the power available to a turbine is very sensitive to the inflow velocity. The power generated by a turbine $\left(P_{\text {mech }}\right)$ is calculated using the rotational speed and torque on the shaft of the device.

$$
P_{\text {mech }}=Q \omega
$$

where $Q$ is the torque $(\mathrm{Nm})$, and $\omega$ is the rotational speed ( $\mathrm{rad} / \mathrm{s})$. In order to quantify the proportion of power captured by a TEC, a non-dimensional number defined as the power coefficient $\left(C_{p}\right)$ is typically used.

$$
C_{P}=\frac{P_{\text {mech }}}{P_{K E}}=\frac{\text { Turbine power }}{\text { Power in the flow }}
$$

The power coefficient is a measure of the effectiveness of a turbine at a specific flow velocity and is generally presented as a function of the turbine tip speed ratio. The tip speed ratio can be defined as the ratio of the turbine rotational speed at the blade tip to the inflow velocity.

$$
\lambda=R \omega / U_{0}
$$

where $\mathrm{R}$ is the turbine radius.

The thrust on the turbine can also be non-dimensionalised to give the coefficient of thrust $\left(C_{T}\right)$.

$$
C_{T}=\frac{\mathrm{T}}{\frac{1}{2} \rho A U_{0}^{2}}
$$

where $\mathrm{T}$ is the thrust force measured on the turbine.

The performance of a tidal turbine can be described by plotting the $C_{P}-\lambda$ curve. This information can be used along with the predicted flow conditions at a tidal site to forecast the amount of power that can be produced by a tidal device. In order to determine the $C_{P}-\lambda$ performance curve of the Evopod model, a set of experiments varying the model torque-speed settings were carried out. The variable resistor bank incorporated into the model provided a method of controlling the torque and rotational speed of the rotor. Towing tests were carried out for a range of resistance settings at a constant towing speed. The tests were repeated for three towing speeds $(0.9,1.1$ and $1.2 \mathrm{~m} / \mathrm{s})$, chosen to represent the flow speed a full scale tidal device would be operational in $(2.9-3.8 \mathrm{~m} / \mathrm{s})$ and to overlap with flow speeds that the large scale model would be exposed to at the Portaferry tidal test site (peak flows of $1.2 \mathrm{~m} / \mathrm{s}$ ). The corresponding Froude number are thus between 0.12 to 0.16 , and the Reynolds number range between $6.8 \times 10^{5}$ and $9.0 \times 10^{5}$, for the range of towing speeds selected.

Figure 10 shows $C_{p}-\lambda$ curves calculated for each towing speed. The experimental results are compared with turbine performance predictions from Oceanflow Energy using WT_Perf, a blade element momentum theory (BEMT) code (Buhl Jr., 2004). WT_Perf was developed by the National Renewable Energy Laboratory (NREL) to predict the performance characteristics of a turbine (Chehouri et al., 2015; Lee et al., 2012; Muñoz et al., 2014). The WT_Perf results presented in Figure 10 are based on a $1 \mathrm{~m} / \mathrm{s}$ inflow velocity and it is assumed that the turbine is operating in an undisturbed flow (i.e. any potential influence of the Evopod support structure on turbine performance has not been considered). 


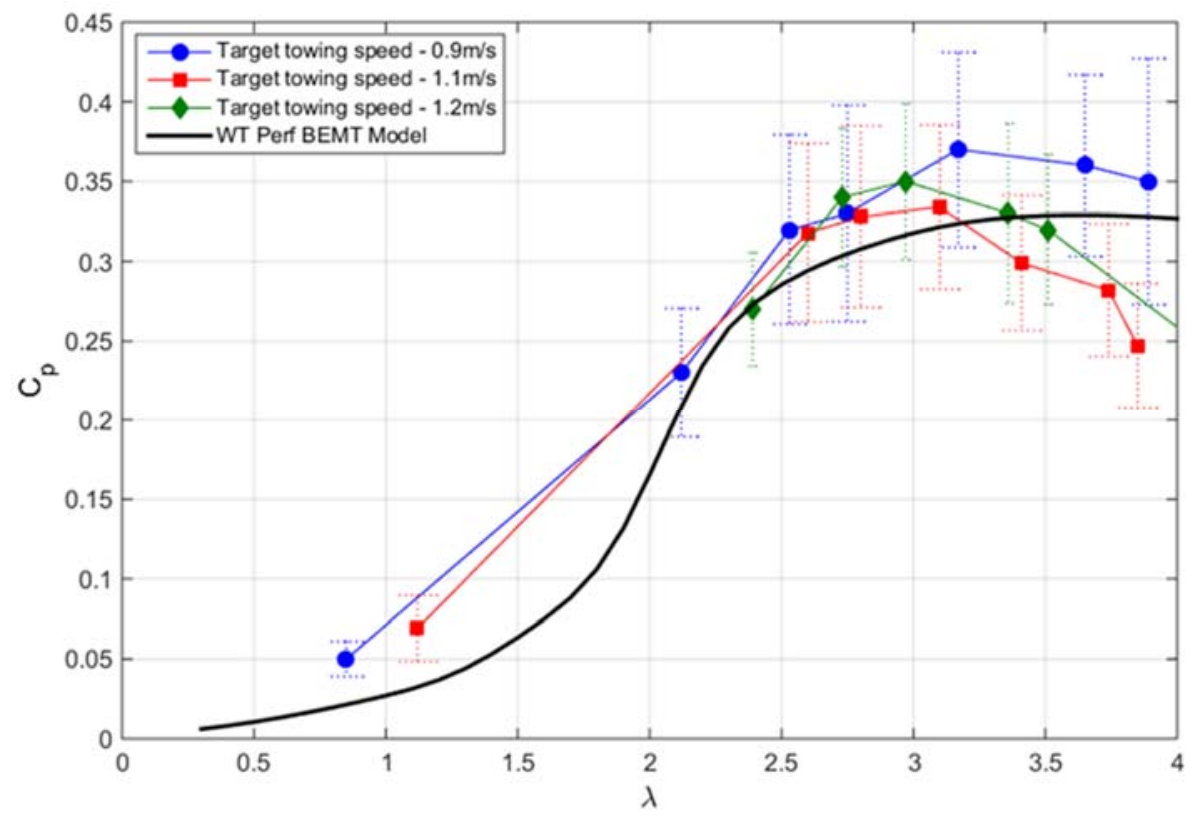

Figure 10: Power coefficient $\left(C_{p}\right)$ versus tip-speed ratio $(\lambda)$ performance curves for the model for target towing speeds of $0.9 \mathrm{~m} / \mathrm{s}, 1.1 \mathrm{~m} / \mathrm{s}$ and $1.2 \mathrm{~m} / \mathrm{s}$ ( $95 \%$ confidence interval indicated by the error bars).

It can be seen from Figure 10 that, as the towing speed increases from $0.9 \mathrm{~m} / \mathrm{s}$ to $1.2 \mathrm{~m} / \mathrm{s}$, the $C_{p}$ curves remain similar (within the bounds of uncertainty) over the operational range of the turbine. The results show that the maximum $C_{p}$ values $(0.33-0.37)$ are largely unaffected by the towing speed and occurred at roughly the same $\lambda$. The $C_{p}-\lambda$ curve predicted using WT_Perf falls within the bounds of uncertainty of the measured data points.

The maximum mechanical power generated by the model was $576 \mathrm{~W}$. This corresponded to the maximum $C_{p}$ value of 0.35 at the fastest towing speed. Table 4 lists the mechanical power generated for maximum values of $C_{p}$ for each towing speed. The results presented in Table 4 and Table 5 are based on values averaged over a single run.

Table 4: Performance parameters for the Evopod model.

\begin{tabular}{|c|c|c|c|c|}
\hline \multirow{2}{*}{$\begin{array}{c}\text { Target towing } \\
\text { speed } \\
\text { (m/s) }\end{array}$} & $\begin{array}{c}\text { Maximum } \\
\boldsymbol{C}_{\boldsymbol{p}}\end{array}$ & $\boldsymbol{\lambda}$ & \multicolumn{2}{|c|}{ Mechanical power (W) } \\
\cline { 4 - 5 } & & Average & $\begin{array}{c}\text { Standard } \\
\text { deviation }\end{array}$ \\
\hline 0.9 & 0.37 & 3.2 & 241 & 15 \\
\hline 1.1 & 0.33 & 3.1 & 393 & 35 \\
\hline 1.2 & 0.35 & 3.0 & 576 & 26 \\
\hline
\end{tabular}

The results exemplify the sensitivity of the power produced by a tidal turbine to a relatively small difference in inflow velocity. Table 4 illustrates that the average mechanical power produced at a towing speed of $0.9 \mathrm{~m} / \mathrm{s}$ is less than $50 \%$ of the power produced at a towing speed of $1.2 \mathrm{~m} / \mathrm{s}$. A set resistance was selected and held constant during the subsequent wake mapping tests to maintain a similar $C_{p}$ for all towing speeds. This provided an opportunity to examine the sensitivity of the wake to the model performance. Table 5 presents a summary of the turbine performance results for each target towing speed during the tests, for the chosen model resistance setting. 
Table 5: Performance parameters for the Evopod model during the wake mapping tests.

\begin{tabular}{|c|c|c|c|c|}
\hline \multirow{2}{*}{$\begin{array}{l}\text { Target towing } \\
\text { speed } \\
(\mathrm{m} / \mathrm{s})\end{array}$} & \multirow{2}{*}{$C_{p}$} & \multirow{2}{*}{$\lambda$} & \multicolumn{2}{|c|}{ Mechanical power (W) } \\
\hline & & & Average & $\begin{array}{l}\text { Standard } \\
\text { deviation }\end{array}$ \\
\hline 0.9 & 0.32 & 2.5 & 200 & 21 \\
\hline 1.1 & 0.33 & 3.1 & 393 & 35 \\
\hline 1.2 & 0.33 & 3.4 & 522 & 36 \\
\hline
\end{tabular}

Unfortunately a thrust measurement was not available from the large scale towing experiments. The WT_Perf model was used to estimate the thrust force on the turbine based on the turbine foil shape and rotational speed at each towing speed (estimated from experimental data). The predicted thrust coefficient values were $0.64,0.69$ and 0.71 for the three target towing speed $(0.9 \mathrm{~m} / \mathrm{s}, 1.1 \mathrm{~m} / \mathrm{s}$ and $1.2 \mathrm{~m} / \mathrm{s})$, respectively. The predicted $C_{T}$ values do not take the device support structure into account. However, a previous experimental study carried out at Newcastle University on a 1:40 th scale Evopod model demonstrated that the drag on the device was significantly reduced when the turbine was in stall mode (Mackie, 2008).

\subsection{Wake characteristics for varying inflow speeds}

The axial velocity deficit results, calculated along a horizontal plane coinciding with the turbine's axis (as marked in Figure 4) for each towing speed, are presented in Figure 11. To improve interpretation of the wake characteristics, the results collected at each measurement point were interpolated to provide 2D contour plots. The objective of data interpolation was to highlight any clear trend in the global wake characteristics. Previous laboratory experiments have found that the velocity deficit profiles in the wake of a turbine generally follow a Gaussian shaped curve (Sun, 2008). As a first estimation, a spline interpolation technique was chosen providing the closest fit to a Gaussian curve. It should be noted that measurements were not obtained at a lateral distance of $0.75 \mathrm{D}$ for downstream distances of $0.5 \mathrm{D}$ and $1 \mathrm{D}$, resulting in a zero deficit at these locations (Figure 11). 

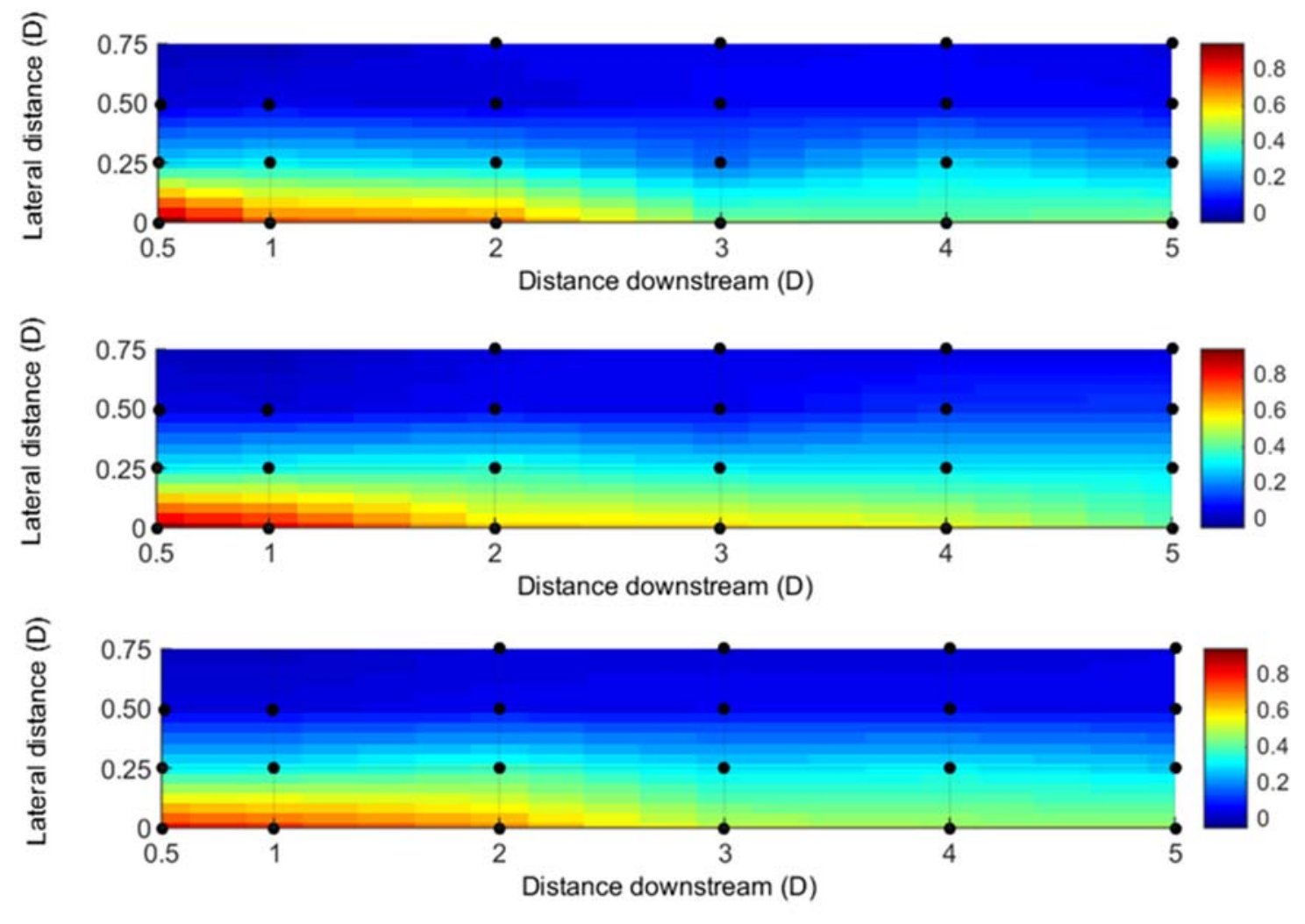

Figure 11: Axial velocity deficit ( $u_{\text {deficit }}$ ) results along the turbine's horizontal axial plane, at target towing speeds of $0.9 \mathrm{~m} / \mathrm{s}$ (top), $1.1 \mathrm{~m} / \mathrm{s}$ (centre) and $1.2 \mathrm{~m} / \mathrm{s}$ (bottom).

In general, the greatest reduction in velocity occurs directly behind the nacelle and is contained largely within a lateral distance of $0.25 \mathrm{D}$ from the turbine's axis. The general trend of wake recovery is a region of rapid recovery (up to 3D), followed by a region of unchanging or gradually reducing velocity deficit (between 3D and 5D). Rose et al. (2011) observed a similar trend in small scale experimental tests carried out in the laboratory, with a rapid recovery between $2 \mathrm{D}$ and $8 \mathrm{D}$ and a much slower recovery beyond. To allow closer examination of the results, the axial velocity deficit results along the turbine axis for each towing speed are presented in Figure 12. Wake decay functions, as predicted by Tennekes and Lumley (1972) for plane and axisymmetric wakes, are also plotted in Figure 12. The plane and axisymmetric wake decay functions were selected with the argument that the struts of Evopod produce a plane wake as a first approximation, and the rotor produces an axisymmetric wake as disc type theory is often applied to tidal turbines. 


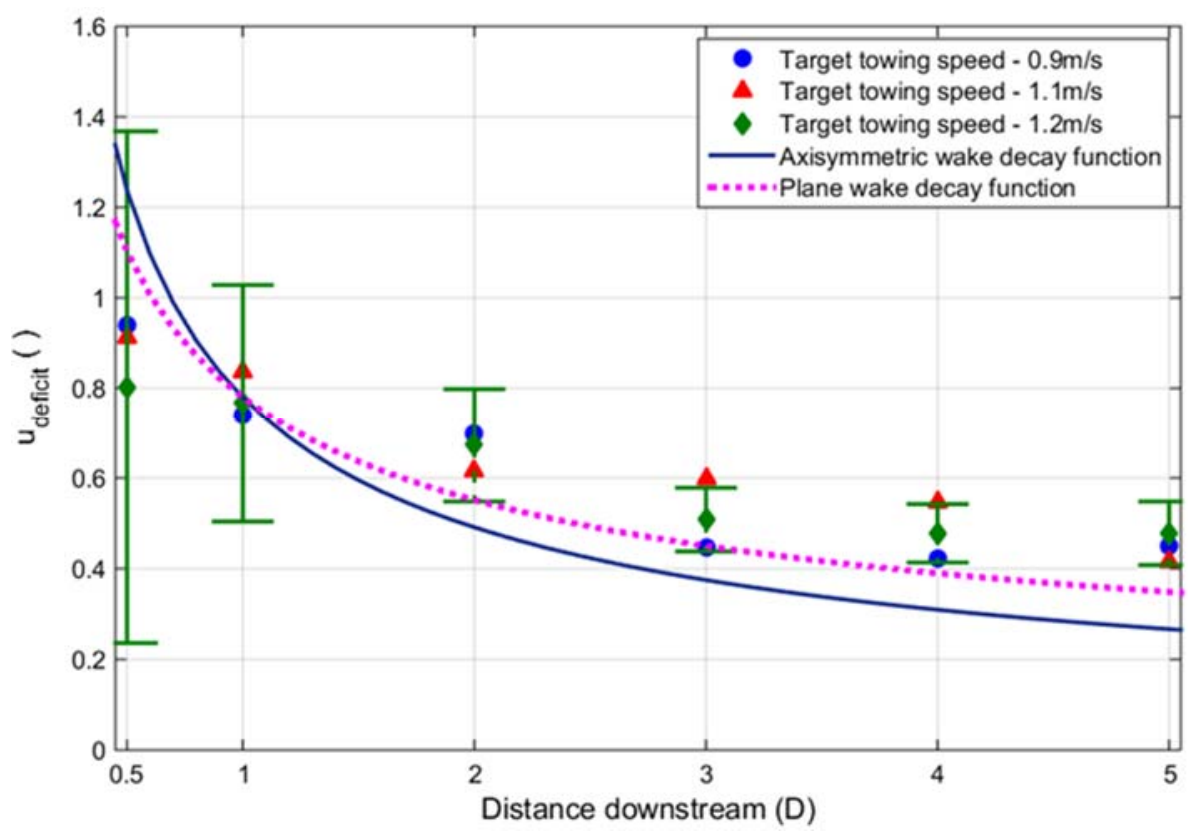

Figure 12: Axial velocity deficit ( $\left.u_{\text {deficit }}\right)$ along the turbine axis for the three target towing speeds $(95 \%$ confidence interval indicated by the error bars; error bars only included for a towing speed of $1.2 \mathrm{~m} / \mathrm{s}$, but are indicative of other speeds).

It can be seen from Figure 12 that the velocity deficit results are similar for all of the towing speeds and that marginal differences are within the bounds of uncertainty. The high uncertainty at $0.5 \mathrm{D}$ is due to the large standard deviation of the measured wake velocity measurement. These results suggest that the wake velocity deficit characteristics are directly related to the efficiency of the turbine, measured using the $C_{p}$ value and less influenced by the magnitude of power production or the tip speed ratio characteristics of the device (Table 5). The wake decay functions plotted do not achieve a good fit with the measured data points. There are a number of arguments for the discrepancy. For instance, it could be argued that the wake created by the rotor is the inverse of an axisymmetric plume, rather than a disc, since the rotor removes momentum from the flow, unlike a disc where it is converted into turbulence and eventually dissipated.

The turbulence characteristics of the measured wake are described using the turbulence intensity (Equation 3 ) and turbulent kinetic energy parameters. The turbulent kinetic energy (TKE) is calculated using the Reynolds normal stresses.

$$
T K E=1 / 2\left(\overline{u^{\prime 2}}+\overline{v^{\prime 2}}+\overline{w^{\prime 2}}\right)
$$

where $u^{\prime}, v^{\prime}$ and $w^{\prime}$ are the fluctuating components of the $u, v$ and $w$ velocity signals.

Figure 13 presents the axial turbulence intensities for each target towing speed. In order to further investigate the turbulence characteristics of the wake, the TKE results are presented in Figure 14. TKE is a measure of the mean kinetic energy in the flow associated with the turbulent fluctuations. 


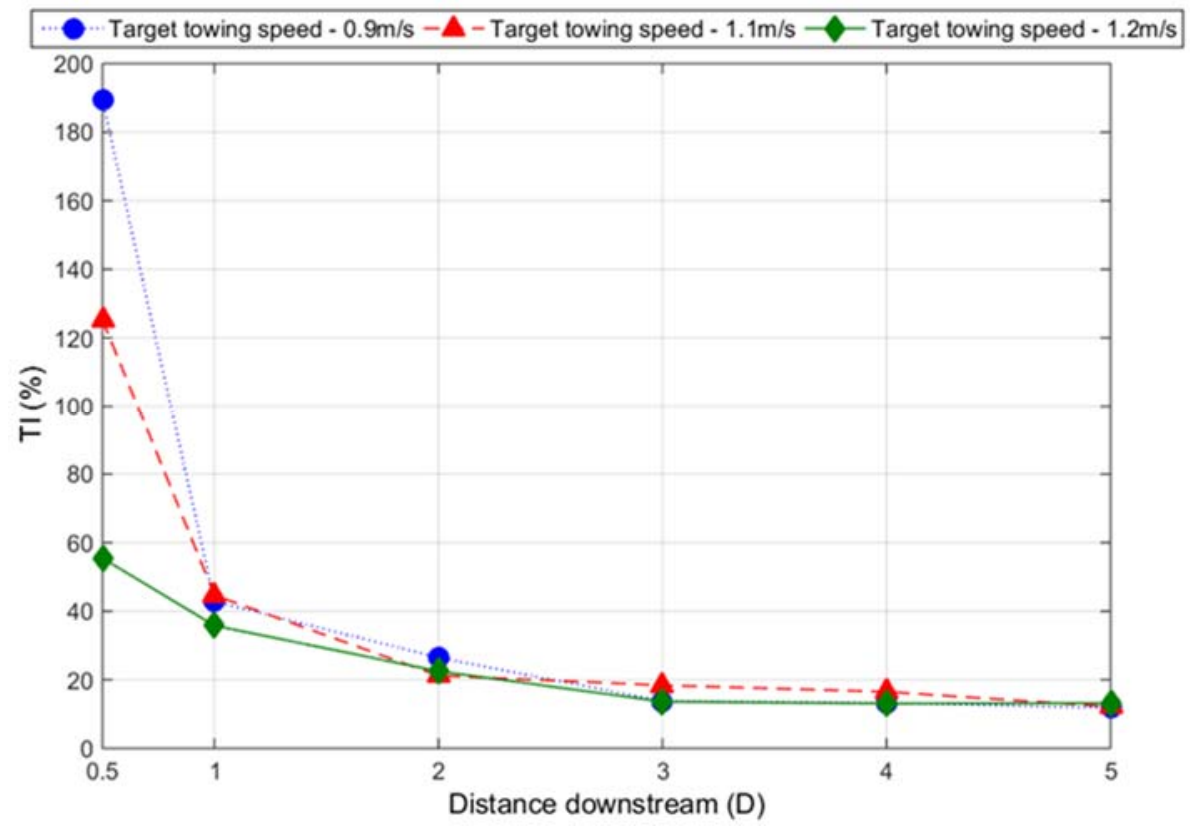

Figure 13: Turbulence intensity (TI) along the turbine axis for the three target towing speeds.

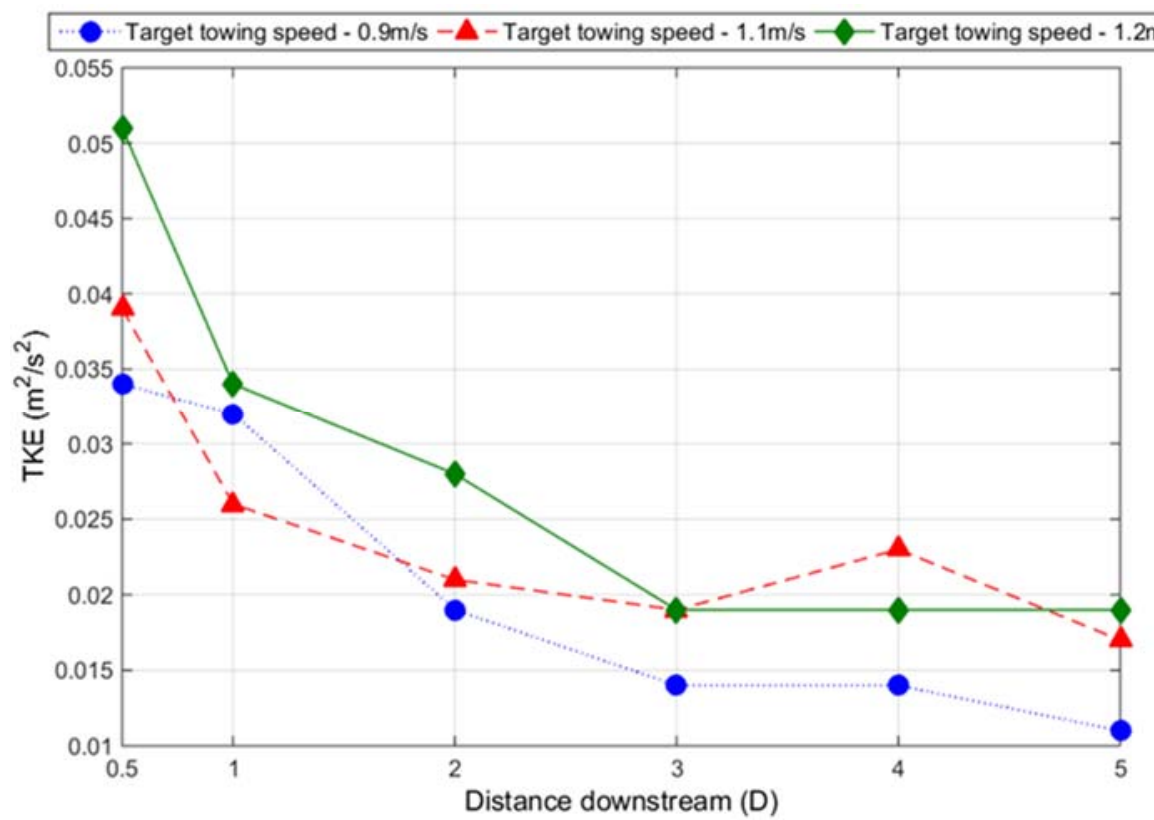

Figure 14: Turbulence kinetic energy (TKE) results along the turbine axis for the three target towing speeds. 


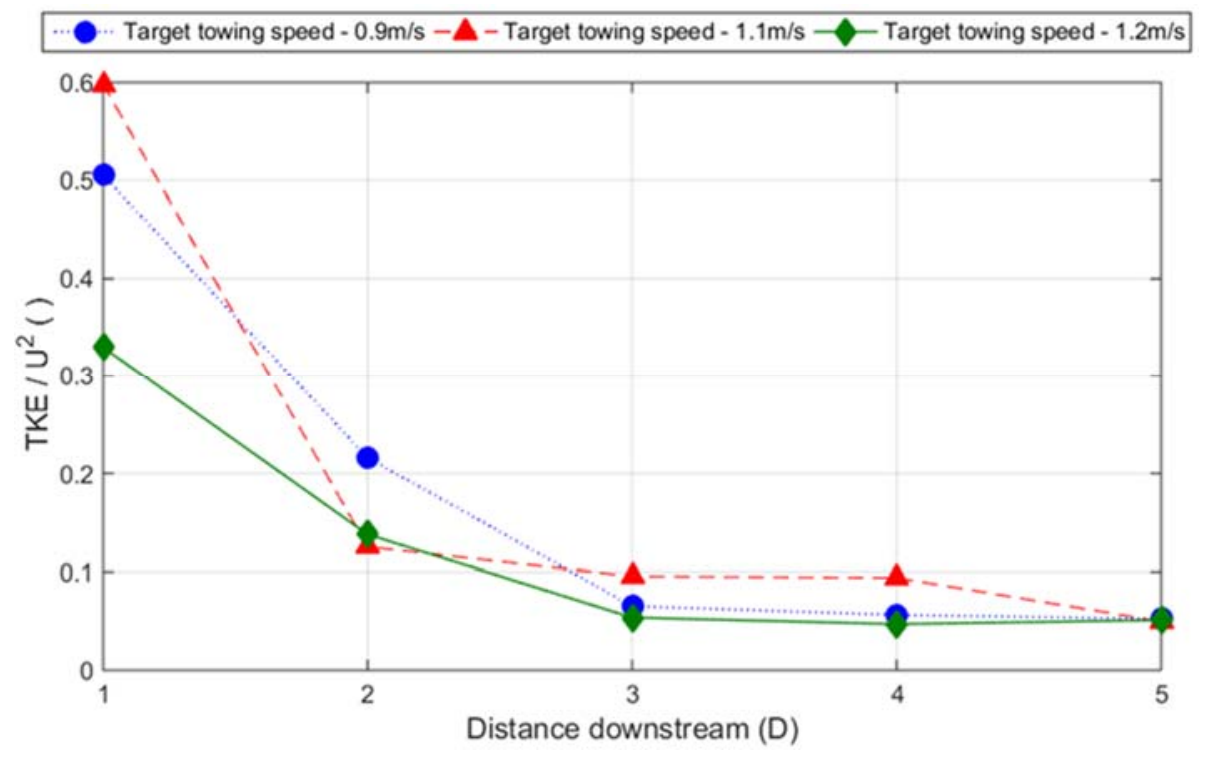

Figure 15: Normalised turbulence kinetic energy results along the turbine axis for the three target towing speeds, between 1D and 5D downstream of the rotor.

Within the downstream region, the turbulence intensity values range between 36 and $45 \%$ at 1D, to approximately $12 \%$ for all towing speeds at 5D downstream. Significantly elevated turbulence intensities were calculated directly behind the model and were most pronounced at the slowest towing speed. Within a short distance these elevated values decreased rapidly. The apparently high turbulence intensity results at $0.5 \mathrm{D}$ downstream are attributed to a combination of a highly fluctuating velocity component (large standard deviation) and a low mean velocity directly behind the nacelle. Normalised TKE results display a similar trend to turbulence intensity result presented, with a significantly elevated value at 0.5D (not presented in Figure 15) followed by a significant reduction in magnitude to values in the range of 0.05 at $5 \mathrm{D}$ downstream.

\section{Overview of wake characteristics}

The deficit of the mean velocity along the turbine axis was $0.80-0.94$ at $1 \mathrm{D}$ downstream of the rotor, with distance downstream the velocity recovered to $0.48-0.42$ at $5 \mathrm{D}$. The deficit results indicate that the axial component of velocity in the wake is still considerably lower than the inflow velocity and a greater distance downstream is required for the wake velocity to recover. The velocity deficit at a lateral distance of $0.25 \mathrm{D}$ from the turbine axis increases by approximately $10 \%$ between $0.5 \mathrm{D}$ and $2 \mathrm{D}$ downstream. Further downstream, the velocity deficit reduces, but signs of wake expansion are observed with marginally higher velocity deficit results recorded at a lateral distance of $0.5 \mathrm{D}$ from the turbine axis at $4 \mathrm{D}$ and $5 \mathrm{D}$ downstream. This trend was similar for all inflow speeds.

At a distance of 5D downstream, a velocity deficit of greater than $40 \%$ was observed. This deficit is within the range of values measured in other experimental studies in the wake of a tidal turbine, along the wake centreline between 4 to 5D downstream of the rotor (Maganga et al., 2010; Rose et al., 2011; Stallard et al., 2015). A full recovery of the wake is not expected by $5 \mathrm{D}$ downstream. Experimental studies carried out by Rose et al. (2011) in the laboratory found that for certain rotor configurations the wake extended up to 25D downstream of the model. Bahaj et al. (2007) also found that at 20D downstream the wake velocity remained at 90 percent of the inflow velocity. The large scale towing tests have insufficient measurements remote from the turbine to allow full investigation of far wake recovery. 
A progressive reduction in turbulence intensity and TKE values was recorded between $0.5 \mathrm{D}$ $\left(0.039-0.051 \mathrm{~m}^{2} / \mathrm{s}^{2}\right)$ and 3D $\left(0.014-0.019 \mathrm{~m}^{2} / \mathrm{s}^{2}\right)$ downstream of the turbine. After a distance of $3 \mathrm{D}$ downstream, the magnitude of the results gradually decreases with increasing distance from the turbine $\left(0.011-0.019 \mathrm{~m}^{2} / \mathrm{s}^{2}\right.$ at $5 \mathrm{D}$ downstream). These results compare to ambient TKE levels of $<0.006 \mathrm{~m}^{2} / \mathrm{s}^{2}$ recorded during the preliminary towing tests. The trend in wake TKE levels loosely follows the same pattern as the velocity deficit results, which show a zone of rapid recovery, followed by a zone of minimal change. It is likely that the increased turbulent fluctuations directly behind the device act to aid the velocity recovery within this zone (up to $3 \mathrm{D}$ ), and once they decrease the velocity recovery slows down in the region beyond 3D downstream. Due to the fact that flow was created artificially, by towing the device through the fluid, the ambient turbulence intensity in the lake was relatively low $(<2 \%)$, in comparison to turbulence intensity values measured at a tidal site, which have been quoted in the range of $10 \%$ and above (McCann et al., 2008; Thomson et al., 2010). Studies have shown that the recovery of velocity in the wake of a TEC is faster in flows with higher ambient turbulence intensity (MacLeod et al., 2002). These factors suggest that the artificially low ambient turbulence intensities in the lake have a detrimental influence on wake recovery. It is anticipated that the wake would recover more rapidly if the ambient turbulence intensities were higher.

\section{Conclusions}

A new large scale tidal turbine test facility, including a turbine towing rig and a traversable measurement platform, was designed and built to conduct large scale model tidal turbine performance tests including wake field measurements. An experimental test campaign investigating the hydrodynamic performance of the $1: 10^{\text {th }}$ scale Evopod tidal turbine was conducted.

It was demonstrated that varying the inflow speed yielded little difference in the maximum power coefficients achieved and that the maxima occurred at approximately the same tip speed ratio. The maximum mechanical power generated by Evopod during performance tests was $576 \mathrm{~W}$. This corresponded to the maximum power coefficient of 0.35 at a towing speed of $1.2 \mathrm{~m} / \mathrm{s}$. Increasing the inflow speed had an influence on the turbulence characteristics in the wake, with higher TKE values for a towing speed of $1.2 \mathrm{~m} / \mathrm{s}$ compared to $0.9 \mathrm{~m} / \mathrm{s}$. In terms of turbulence intensity however, from 1D downstream the difference is within the measurement accuracy, thus again not inflow speed dependent.

The difference in wake recovery between the various towing speeds was within the measurement accuracy and thus considered independent of inflow speed. The general trend of wake recovery along the turbine axis showed a region of rapid recovery between 0.5 and 3D downstream, with velocity deficit values of $0.80-0.94$ and $0.44-0.60$, respectively. This was followed by a region of unchanging or gradually reducing velocity deficit between $3 \mathrm{D}$ and $5 \mathrm{D}$. The plane and axisymmetric wake decay functions plotted did not achieve a good fit to the measured wake. Additional studies are required to assess the applicability of different wake decay functions to the wake created by a tidal energy conversion device. The wake recovery in the lake is likely to be impacted by the artificially low level of ambient turbulence in the surrounding fluid. Future work is needed to investigate the influence of ambient turbulence levels on the persistence of downstream wake effects.

The greatest reduction in velocity occurred directly behind the nacelle and was contained largely within a lateral distance of $0.25 \mathrm{D}$ from the turbine's axis. The velocity deficit results at a lateral distance of $0.25 \mathrm{D}$ from the turbine axis increase between $0.5 \mathrm{D}$ and $2 \mathrm{D}$ downstream suggesting the wake is expanding laterally. The expansion of the wake within this region 
coincides with the rapid recovery in velocity deficit seen along the turbine axis. Further studies would benefit from a more comprehensive map of ADV measurements to examine the lateral expansion of the wake more clearly.

The towing test facility established may be used for a wide range of TEC-related tests. The towing tests allow the performance of a tidal model in steady uniform flow conditions to be quantified, before adding the complexity of the unsteady non-uniform inflow conditions encountered at a tidal test site. Subject to the model instrumentation, it is possible to record power, thrust and wake characteristics simultaneously. In terms of wake mapping, the ability to accurately measure the flow field is essential and this becomes increasingly complicated at larger scales. Finding the most suitable velocity measurement instrument to measure the wake of a large scale turbine in the tidal flow is important. Consequently, and with a view to sea trials, future towing tests may investigate the potential of acoustic Doppler profilers to characterise the wake of a large scale model tidal turbine.

\section{Acknowledgements}

The authors wish to acknowledge the Engineering and Physical Sciences Research Council (EPSRC) for their support of the SuperGen Marine Energy Research Consortium - Phase 2, which funded this work. The authors acknowledge Oceanflow Energy Limited for their support and for the use of their 1:10 $0^{\text {th }}$ scale Evopod model. The authors gratefully acknowledge the use of the WT_Perf output provided by Graeme Mackie and Roger Cox from Oceanflow Energy Ltd, Newcastle.

\section{References}

Afgan, I., McNaughton, J., Rolfo, S., Apsley, D.D., Stallard, T., Stansby, P., 2013. Turbulent flow and loading on a tidal stream turbine by LES and RANS. Int. J. Heat Fluid Flow 43, 96-108.

Atcheson, M., 2013. A large scale model experimental study of tidal turbines in steady uniform flow (Ph.D. thesis). School of Planning, Architecture and Civil Engineering, Queen's University Belfast.

Bahaj, A.S., Myers, L.E., Thomson, M., Jorge, N., 2007. Characterising the wake of horizontal axis marine current turbines, in: Falcao, A. (Ed.), Proceedings of the Seventh European Wave and Tidal Energy Conference, Porto, Portugal. Porto, Portugal.

Birjandi, A.H., Woods, J., Bibeau, E.L., 2012. Investigation of macro-turbulent flow structures interaction with a vertical hydrokinetic river turbine. Renew. Energy 48, 183-192.

Boake, C.B., Atcheson, M., Bryden, I.G., Whittaker, T.W., 2009. Selection of a large model scale field wave and tidal test site in Strangford Lough, UK, in: Proceedings from the 1st International Conference on Sustainable Power Generation and Supply (SUPERGEN). Nanjing, China, pp. 1-7.

Buhl Jr., M.L., 2004. WT_Perf User's Guide. National Renewable Energy Laboratory.

Builjtes, P.J.H., 1978. The interaction of windmill wakes, in: Proceedings of the 2nd International Symposium on Wind Energy Systems. Volume 1. British Hydromechanics Research Association, p. B5-49 to B5-58., Amsterdam, Netherlands. 
Chamorro, L.P., Hill, C., Morton, S., Ellis, C., Arndt, R.E. a, Sotiropoulos, F., 2013. On the interaction between a turbulent open channel flow and an axial-flow turbine. J. Fluid Mech. 716, 658-670.

Chehouri, A., Younes, R., llinca, A., Perron, J., 2015. Review of performance optimization techniques applied to wind turbines. Appl. Energy 142, 361-388.

Donoho, D.L., Johnstone, I.M., 1994. Ideal spatial adaptation by wavelet shrinkage. Biometrika $81,425-55$.

Good, A., Hamill, G., Whittaker, T., Robinson, D., 2011. PIV Analysis of the Near Wake of a Tidal Turbine, in: International Offshore and Polar Engineering Conference. Maui, Hawaii, USA, pp. 770-776.

Goring, D.G., Nikora, V.I., 2002. Despiking acoustic Doppler velocimeter data. J. Hydraul. Eng. $128,117-126$.

Harrison, M., Batten, W., Blunden, L., Myers, L.., Bahaj, A.S., 2008. Comparisons of a large tidal turbine array using boundary layer and field wake interaction models, in: Proceedings of the 2nd International Conference on Ocean Energy. Brest, France.

Kang, S., Yang, X., Sotiropoulos, F., 2014. On the onset of wake meandering for an axial flow turbine in a turbulent open channel flow. J. Fluid Mech. 744, 376-403.

Lee, J.H., Park, S., Kim, D.H., Rhee, S.H., Kim, M.-C., 2012. Computational methods for performance analysis of horizontal axis tidal stream turbines. Appl. Energy 98, 512-523.

Lissaman, P.B.S., 1979. Energy effectiveness of arbitrary arrays of wind turbines. J. Energy 3, 323-328.

Lohrmann, A., Cabrera, R., Kraus, N.C., 1994. Acoustic-Doppler Velocimeter (ADV) for laboratory use, in: Proceedings Fundamentals and Advancements in Hydraulic Measurements and Experimentation. ASCE, pp. 351-365.

Mackie, G.C., 2008. Development of Evopod tidal stream turbine, in: Royal Institute of Naval Architects (RINA) - Marine Renewable Energy International Conference. London.

MacLeod, A.J., Barnes, S., Rados, K.G., Bryden, I.G., 2002. Wake effects in tidal current turbine farms, in: Proceedings of the International Conference of Marine Renewable Energy. Newcastle upon Tyne, UK, pp. 49-53.

Maganga, F., Pinon, G., Germain, G., 2010. Wake properties characterisation of marine current turbines. Int. Conf. Ocean Energy 2-6.

McCann, G., Thomson, M.D., Hitchcock, S., 2008. Implications of site-specific conditions on the prediction of loading and power performance of a tidal stream device, in: Proceedings of the 2nd International Conference on Ocean Energy. Brest, France.

Medici, D., Alfredsson, P.H., 2005. Measurements on a wind turbine wake: 3D effects and bluff body vortex shedding. Wind Energy 219-236. 
Mori, N., Suzuki, T., Kakuno, S., 2007. Noise of acoustic Doppler velocimeter data in bubbly flows. J. Eng. Mech. ASCE 133, 122.

Muñoz, A.H., Chiang, L.E., la Jara, E.A. De, 2014. A design tool and fabrication guidelines for small low cost horizontal axis hydrokinetic turbines. Energy Sustain. Dev. 22, 21-33.

Mycek, P., Gaurier, B., Germain, G., Pinon, G., Rivoalen, E., 2014. Experimental study of the turbulence intensity effects on marine current turbines behaviour. Part I: One single turbine. Renew. Energy 66, 729-746.

Myers, L.E., Bahaj, A.S., 2010. Experimental analysis of the flow field around horizontal axis tidal turbines by use of scale mesh disk rotor simulators. Ocean Eng. 218-227.

Myers, L.E., Bahaj, A.S., 2009. Near wake properties of horizontal axis marine current turbines, in: Proceedings of the 8th European Wave and Tidal Energy Conference. Uppsala, Sweden.

Myers, L.E., Bahaj, A.S., 2008. Scale reproduction of the flow field for tidal energy converters, in: In. 10th World Renewable Energy Congress. Glasgow, UK.

Oceanflow Energy, 2007. Oceanflow Energy [WWW Document]. URL http://www.oceanflowenergy.com/index.html (accessed 5.26.15).

Rose, S., Ordonez, S., Lee, K.H., Johnstone, C., Jo, C.H., McCombes, T., Grant, A., 2011. Tidal turbine wakes: Small scale experimental and initial computational modelling, in: Proceedings of the 9th European Wave and Tidal Energy Conference. Southampton, UK.

Sforza, P.M., Sheerin, P., Smorto, M., 1981. Three-dimensional wakes of simulated wind turbines. AIAA J. 19, 1101-1107.

SonTek, 2001. Acoustic Doppler Velocimeter (ADV) Principles of Operation, SonTek Technical Notes. San Diego, California, USA.

Stallard, T., Feng, T., Stansby, P.K., 2015. Experimental study of the mean wake of a tidal stream rotor in a shallow turbulent flow. J. Fluids Struct. 54, 235-246.

Sun, X., 2008. Numerical and experimental investigation of tidal current energy extraction (Ph.D. Thesis). School of Engineering, The University of Edinburgh.

SuperGen Marine, 2012. SuperGen Marine Energy Research Consortium, Phase II [WWW Document]. URL http://www.supergen-marine.org.uk/drupal/content/supergen-phase-2 (accessed 2.2.12).

Tedds, S.C., Owen, I., Poole, R.J., 2014. Near-wake characteristics of a model horizontal axis tidal stream turbine. Renew. Energy 63, 222-235.

Tedds, S.C., Poole, R.J., Owen, I., Natjafian, G., Mason-Jones, A., Morris, C., O’Doherty, T., O'Doherty, D.M., 2011. Experimental investigation of horizontal axis tidal stream turbines, in: Proceedings of the 9th European Wave and Tidal Energy Conference. Southampton, UK. 
Tennekes, H., Lumley, J.L., 1972. A First Course in Turbulence. The Massachusetts Institute of Technology, Cambridge, Massachusetts, and London, England.

Thomson, J., Richmond, M., Polagye, B., Durgesh, V., 2010. Quantifying turbulence for tidal power applications, in: Proceedings of Oceans 2010. Seattle, Washington, US, pp. 20-23.

Vermeer, L., Sørensen, J., Crespo, A., 2003. Wind turbine wake aerodynamics. Prog. Aerosp. Sci. 39, 467-510.

Wahl, T.L., 2003. Discussions of "Despiking acoustic doppler velocimeter data" by Derek G. Goring and Vladimir I. Nikora. J. Hydraul. Eng. 128, 484-488.

Whelan, J.I., Graham, J.M.R., Peiró, J., 2009. A free-surface and blockage correction for tidal turbines. J. Fluid Mech. 624, 281. 